\title{
Derecho natural y derecho legal en Aristóteles
}

\author{
JoÃo HobUSS \\ Departamento de Filosofía \\ Universidad Federal de Pelotas \\ joao.hobuss@ufpel.edu.br
}

\begin{abstract}
Resumen: Uno de los pasajes más complejos de la Ethica Nicomachea hace referencia al derecho natural. En las pocas líneas que le dedica Aristóteles al problema, sustenta una concepción que parece contradecir toda una lectura concerniente al derecho natural, centrada en su carácter inmutable. Este artículo intenta reconstruir la argumentación aristotélica que se encuentra en las éticas y en la Retórica, tratando de mostrar que, más allá de una aparente contradicción, es posible encontrar una tesis coherente y satisfactoria acerca del derecho natural a partir de lo que sucede "la mayoría de las veces" (hõs epì tò polú ), lo que tornaría comprensible su mutabilidad.
\end{abstract}

Palabras clave: justo por naturaleza, justo por convención, hõs epì tò polú, bien común

\begin{abstract}
One of the most complex passages in the Ethica Nicomachea deals with natural right. In the few lines dedicated by Aristotle to this issue he maintains a conception that seems to contradict the understanding of natural right focused on its perpetual nature. This paper will try to reconstruct the aristotelian argumentation in his ethics and in the Rhetoric in order to try to demonstrate that beyond an apparent contradiction it is possible to find a coherent and satisfactory thesis about natural right from what happens "for the most part" (hõs epì tò polú), which would turn understandable its variability.
\end{abstract}

Key words: justice by nature, justice by law, hõs epì tò polú, common good

Los fragmentos más emblemáticos y de gran controversia de la Ethica Nicomachea son, sin duda, los que se refieren al derecho natural. Las pocas líneas ${ }^{1}$ que le dedica Aristóteles a este problema exhiben un variado abanico de cuestiones, y no deja de causar sorpresa y admiración tener a la vista un abordaje que, en primera instancia, contradice toda una concepción del derecho natural en relación con una de sus características fundamentales: su carácter inmutable, no sujeto a las circunstancias particulares de un determinado país o de una constitución particular, un derecho que se cierne por encima de la inconstancia de las leyes particulares, positivas y variables de una nación frente a las de otra, de una forma de constitución ante otra.

${ }^{1}$ EN V 10, 1134b18-1135a5.

Diánoia, volumen LIV, número 63 (noviembre 2009): pp. 133-155. 
Este artículo explora la forma en que Aristóteles elabora su doctrina acerca de lo justo natural mediante el análisis de algunas interpretaciones de comentaristas del tema, con el fin de ofrecer una solución desde el propio texto aristotélico, no solamente a partir de la Ethica Nicomachea, sino también a partir de los Magna Moralia y de la Retórica: se trata de especificar el modo a través de cual Aristóteles trata la cuestión en cada una de estas obras y de explicar cuál sería, según la Política, la constitución que en todas las partes (pantachoũ) es, por naturaleza, la mejor (hẽ arístẽ). ${ }^{2}$

\section{EN V 10, 1134b18-1135a5}

En este pasaje de la Ethica Nicomachea, Aristóteles empieza por establecer una distinción en el interior de la propia justicia política entre dos especies de justicia, una natural y otra legal: es natural (phusikón) la justicia que tiene la misma fuerza en todos los lugares y no depende de ésta o de aquella opinión; legal (nomikón) es la justicia que puede originarse indiferentemente aquí o allí, pero que, una vez establecida, se impone.

Hecha esta primera distinción, ${ }^{3}$ Aristóteles propone algunas consideraciones:

1. En el parecer de algunos, toda prescripción de orden jurídico pertenece a la llamada justicia legal;

2. Pertenece a la justicia legal por el simple hecho de que la propia idea de natural remite a un carácter necesariamente inmutable y posee, en todos los lugares, la misma fuerza;

3. Eso deriva del hecho comúnmente admitido de que el derecho [positivo] es susceptible de sufrir variaciones;

4. Pero, para Aristóteles, tales aserciones no son del todo verdaderas; el derecho no es esencialmente variable, pues entre los dioses, por ejemplo, la justicia es, en sí misma, inmutable.

5. Entre nosotros, en nuestro mundo sublunar, hay espacio para algo así como lo justo "natural", aunque susceptible de sufrir cambios.

${ }^{2}$ En general, utilizo las traducciones al español de José Luis Calvo Martínez (Ética a Nicómaco), María Isabel Santa Cruz y María Inés Crespo (Política), y Quintín Racionero (Retórica); las eventuales modificaciones son responsabilidad mía.

${ }^{3}$ Volveremos a retornar detalladamente a la argumentación de Aristóteles en el decurso del texto.

Diánoia, vol. LIV, no. 63 (noviembre 2009). 
6. Sin embargo, es posible distinguir entre lo que es natural y lo que no es natural, y entre las cosas que están sujetas a variación se puede observar cuáles de ellas son naturales y cuáles son por ley o convención (consideración que se ilustra mediante la capacidad de ser ambidextros).

7. Así que tanto unas como otras son susceptibles de sufrir variaciones.

8. Ni las reglas de derecho que descansan en la convención y en la conveniencia, ni las que no se fundan en la naturaleza pero dependen de los hombres, son las mismas en todos los lugares, en la medida en que la propia constitución tampoco existe por naturaleza.

9. Sin embargo, según Aristóteles, existe sólo una constitución que es, en todos los lugares, la mejor.

Cada uno de los puntos explicitados está sujeto a una serie de objeciones que debe responder Aristóteles en las obras ya señaladas, buscando la solución de las posibles inconsistencias de su doctrina en torno al derecho natural. En este sentido, el presente texto intenta llamar la atención con respecto al hecho de que lo justo natural en Aristóteles presenta un estatus bien establecido en sus obras éticas [con el respaldo de la Política], mientras que quizá en la Retórica ese estatus no se confirme y contradiga otras obras del corpus aristotelicum. Todavía es necesario destacar que éste quizá puede ser una anticipación precipitada, ya que el tratamiento del derecho natural en la Retórica es motivo de acalorada contienda entre los comentaristas.

\section{El derecho natural en Magna Moralia}

En Magna Moralia (en adelante $M M$ ), obra por lo general reconocida como apócrifa, probablemente escrita por algún discípulo aristotélico, ${ }^{4}$ se nos ofrecen unas pocas líneas que, cotejadas con los pasajes pertinentes de la Retórica y de la Ethica Nicomachea, pueden arrojar un poco de luz sobre la doctrina aristotélica del derecho natural.

En 1194b30, el autor empieza a delinear las principales ideas sobre el asunto manteniendo, en general, lo que está presente en EN

${ }^{4}$ En torno a la discusión sobre la autenticidad de Magna Moralia, y de su uso como referencia en el pensamiento de Aristóteles, véase J.M. Cooper, "The Magna Moralia and Aristotle's Moral Philosophy". 
1134b20-1135a5. En relación con las cosas que son justas, ${ }^{5}$ es lícito afirmar que unas son por naturaleza, otras por ley (Tõn dè dikaíñn estì tà mèn phúsei tà dè nómõi); no obstante, no es lícito afirmar que las cosas que son por naturaleza no pueden sufrir un cambio accidental; pues lo que existe por naturaleza admite mudanza, o sea, permite variabilidad. Esta posibilidad de mudanza o variación es aclarada mediante el ejemplo sobre la capacidad de llegar a ser ambidextro, presente también en $E N$ :

Quiero decir, por ejemplo, que si nos entrenamos en lanzar constantemente con la mano izquierda, nos tornaremos ambidextros; aun así la mano izquierda es tal por naturaleza, y la mano derecha es, todavía, naturalmente superior a la mano izquierda, incluso si hacemos todas las cosas con la izquierda como las hacemos con la derecha. (1194b33-37)

Tal aspecto no significa afirmar que, porque admiten cambios accidentales, tales cosas no sean por naturaleza, prosigue el autor, pues, la mayoría de las veces (hõs epì tò polú) y la mayor parte del tiempo (tòn pleíõ chrónõn), la mano izquierda aún posee sus características de mano izquierda y la derecha de mano derecha, y todo eso ocurre por naturaleza. Por naturaleza, la mano derecha es superior (beltión) a la mano izquierda. La introducción de la expresión hõs epì tò polú refleja una novedad, desde el punto de vista literal con relación a $E N$, como se verá más adelante, en la medida en que ahí no se encuentra esa expresión, aunque es imprescindible subrayar que no se encuentra "literalmente".

Lo mismo que ocurre en el ejemplo de la capacidad de llegar a ser ambidextros sucede con las cosas que son naturalmente justas: aunque el uso cause modificaciones y variaciones, esas cosas que son justas por naturaleza son todavía el tema, pues "lo que es justo de manera continua la mayoría de las veces es, claramente, lo que es justo por

${ }^{5}$ En realidad, hay una aparente diferencia en relación con el pasaje de $E N$ : ahí, la distinción entre lo justo natural y lo justo legal ocurre en el interior de lo justo político, mientras que en $M M$ la distinción acontece en el interior de las cosas justas. Sin embargo, en pasajes inmediatamente anteriores encontramos la afirmación de que lo justo sobre lo cual concierne la investigación es lo justo político (1194b78), y que se asocia lo justo a la comunidad política, pues "la justicia y el hombre justo se refieren al que es políticamente justo" (1194b29-30). Por consiguiente, al afirmar que unas cosas son justas por naturaleza y otras por ley, el autor de $M M$ probablemente tiene en mente la justicia política, que antecede a la introducción de la distinción justo natural y justo legal. 
naturaleza" (1195a3-4). Y eso que es justo por naturaleza es mejor (superior) a lo que es justo por ley, lo justo legal.

Es verdad que la observación de que lo justo por naturaleza es lo justo la mayoría de las veces debe ser matizada de cierto modo, pues Aristóteles no niega por completo la inmutabilidad de aquello que es justo por naturaleza, ya que la mano derecha no deja de ser superior, mejor o más fuerte que la mano izquierda, lo que parece indicar cierta tensión entre la mutabilidad y la inmutabilidad de lo justo por naturaleza.

\section{El derecho natural en la Retórica}

La discusión sobre el derecho natural en la Retórica empieza en I 10; allí Aristóteles trata cuestiones referentes a la acusación y a la defensa; su disquisición tiene como telón de fondo un interés fundamentalmente retórico, ${ }^{6}$ pues busca enumerar y describir las premisas de los silogismos. En este capítulo, por primera vez en la obra, hace alusión al tema objeto de este estudio: "La ley se divide en particular y común. Llamo particular a la ley escrita por la que se gobierna cada ciudad; y común a las leyes no escritas sobre las que parece haber un acuerdo unánime en todos <los pueblos>" (1368b7-9).

Este pasaje es retomado en I 13 1373b4-17, en el interior de una discusión que pretende establecer una clasificación en la que hace referencia a las acciones que son justas e injustas. Se trata del famoso pasaje donde hay una alusión, en la discusión entre ley particular y ley común, a la Antígona de Sófocles. En 1373b4, Aristóteles introduce de nuevo la distinción entre ley particular y ley común, afirmando que entiende por ley particular la ley definida relativa a cada pueblo tomado en su especificidad, de modo que esta ley particular es vista bajo dos aspectos: puede ser tanto escrita como no escrita. ${ }^{7}$ Y la ley común es reconocida inmediatamente como que ley universal,

porque existe ciertamente algo — que todos adivinan (manteúontai)— comúnmente <considerado como $>$ justo o injusto por naturaleza, aunque

${ }^{6}$ Eso es asaz evidente si se observa un poco más adelante (1368b29-32) la afirmación de que el acusador debe considerar, entre todas las cosas que pueden llevarnos a cometer injusticias, aquellas que —en lo que se refiere a la cantidad y a la cualidad - afectan a su adversario; así como, de modo inverso, el defensor debe indicar cuáles no lo afectan.

${ }^{7}$ Sobre la ley escrita, la no escrita y las leyes comunes, véase el excelente libro de Jacqueline de Romilly, La Loi dans la pensée grecque, especialmente las pp. 2549. 
no exista comunidad ni haya acuerdo entre los hombres. Tal como, por ejemplo, lo muestra la Antígona de Sófocles, cuando dice que es de justicia, aunque esté prohibido, enterrar a Polinices, porque ello es justo por naturaleza. (1373b6-11)

Se presenta la misma intención de reafirmar la existencia de una ley que sea universal -en el caso de la tragedia de Sófocles, la repulsa de Antígona al decreto impuesto por Creonte- en los ejemplos dados a continuación, cuando Aristóteles se refiere a Empédocles y a su defensa de la interdicción de matar un animal viviente, "dado que ello no es para unos justo y para otros injusto", pues sería una ley universal válida para todos sin excepción, lo mismo que dice el sofista y retórico Alcidamas $^{8}$ en su Discurso mesenio.

Por fin, una última incidencia en I 15 1375a27-b2. El contexto aquí es muy claro. La intención está orientada a señalar las pruebas no técnicas de persuasión y disuasión en el procedimiento retórico, para utilizarlas de mejor manera en su objetivo propuesto, ya que el foco está centrado en la oratoria jurídica, lo cual refiere, es importante resaltar, a los actos de acusar y defender. En este proceso de persuasión/disuasión, el defensor debe utilizar cualquier procedimiento que le traiga un resultado favorable. Con tal propósito, si las nombradas leyes escritas de la justicia legal no sirvieran, en determinada situación, para la defensa del caso, sería preciso recurrir a la ley universal y a la epieíkeia (equidad), defendiéndolas como lo que es más justo para el caso, en vez de sujetarse a la letra de la ley escrita, para afirmar que "la equidad siempre permanece y nunca cambia, como tampoco la ley común (pues es conforme a la naturaleza), mientras que las leyes escritas < cambian> muchas veces" (1375a31-33). Aristóteles recuerda que ése es el espíritu de Antígona, cuando recusa los decretos procedentes de los hombres e invoca la "ley que no es de hoy, ni de ayer, sino eterna". 9

El problema esencial de estos pasajes sobre el derecho en la Retórica es tratar de saber cómo conciliarlos con los de $M M$ y de $E N$, pues sus argumentos parecen contradecir frontalmente el desarrollo argumentativo de los últimos (en especial, la ausencia de cualquier mención

${ }^{8}$ Como señala Jacques Brunschwig en "Rule and Exception: On the Aristotelian Theory of Equity", p. 145, el discurso de Alcidamas no está presente en los manuscritos, pero fue preservado en un escolio. El discurso en cuestión condena la esclavitud por ser "contraria a la naturaleza y a la intención de Dios". Obviamente, como observa el autor, la tesis está lejos de ser algo que pueda considerarse válido universalmente.

${ }^{9}$ Ret. $1375 \mathrm{~b} 1$.

Diánoia, vol. LIV, no. 63 (noviembre 2009). 
a la variabilidad de lo que es justo por naturaleza). La cuestión que permanece es saber si estas líneas de la Retórica posibilitan una visión digna de confianza ${ }^{10}$ acerca de la teoría de Aristóteles sobre el tema, si pudiéramos realmente tomar los ejemplos referentes a Antígona, Empédocles y Alcidamas como una defensa admisible del derecho natural; lo mismo puede decirse en relación con I 15, precisamente por el hecho de que la defensa del derecho natural, de una ley común, universal, válida incondicionalmente para todos, aparenta ser más un artificio retórico para usar en el ámbito judicial, que una defensa consistente de esta tesis. Si así fuera, ¿deben ser simplemente abandonados los argumentos explicitados en la obra por responder a otro objetivo que no sea el de las obras éticas? Debe ofrecerse, al menos, una respuesta tentativa a dicho problema.

\section{Aristóteles y el derecho natural: en busca de una solución coherente}

Antes de volver a $E N$, es importante poner de manifiesto una posición en relación con usar o no la Retórica ${ }^{11}$ como referencia fundamental en la investigación acerca de la doctrina aristotélica sobre el derecho natural. Una vez hecho eso, será posible sugerir un camino de interpretación más exacto sobre las intenciones reales de Aristóteles.

En primer lugar es necesario volver la mirada a los ya mencionados ejemplos relativos a Antígona y a Empédocles. Empecemos por el último.

$\mathrm{Su}$ tesis sobre la interdicción de matar animales aparece como una de las razones presentadas por Aristóteles para afirmar la existencia de una ley común disociada de la ley particular, pues su estatus se encuen-

\footnotetext{
${ }^{10}$ Sobre eso, véase el erudito y bien fundamentado artículo de Jacques Brunschwig, "Rule and Exception: On the Aristotelian Theory of Equity", ya citado, especialmente las pp. 141-150.

${ }^{11}$ Tal problema es objeto de disenso; por ejemplo, Pierre Aubenque en "La Loi selon Aristote", pp. 152-153, reafirma, por un lado, que se trata de un procedimiento meramente retórico en relación con el pasaje donde aparece el argumento de que si la ley escrita fuera desfavorable a determinada causa ante el tribunal es necesario recurrir a la ley no escrita; por otro, cuando Antígona está en cuestión, señala que la oposición entre la ley particular y la ley común (eterna) está lejos de significar la expresión última de Aristóteles sobre la filosofía del derecho: "Se podría decir, asimismo, que es en oposición a esta concepción, probablemente ya banal en su tiempo, que se constituye la originalidad de la solución que Aristóteles ofrece a este problema [en EN V]. Pueden encontrarse posiciones distintas de Aubenque; por ejemplo, en F.D. Miller Jr., "Aristotle on Natural Law and Justice", y en P. Destrée, "Aristote et la question du droit naturel (EN V, 10, 1134b18-1135a5)".
} 
tra más allá de los decretos específicos de cada ciudad, por el hecho de que posee una validez común a todos, al estar en conformidad con la naturaleza (katà phúsin). En este contexto, tenemos la tesis de Empédocles citada anteriormente, compartida por Aristóteles mismo: "declaran que, para todos los vivientes, la posición es la misma en relación con el derecho, y proclaman que penas inexpiables amenazan a los que atacan a un ser vivo" (D.K., B CXXXV). ${ }^{12}$ Debería haber, desde este punto de vista, "no sólo una comunidad de hombres, entre ellos y los dioses, sino también una comunidad de hombres con las bestias brutas. Pues existe un espíritu único que nos penetra, en forma de un alma, al cosmos entero, y que nos une a ellos". (D.K., B CXXXVI)

De este modo, matarlos y degustarlos consistiría en un acto impío, un acto completamente injusto, pues sería como matar a nuestros familiares. El problema resultante es cómo comprender que Aristóteles pudiera utilizar esta tesis para fundamentar la existencia de la ley natural, pues se trata de una tesis reconocidamente extraña al aristotelismo, y el mismo Aristóteles en la Política (1256b16-22) parece recusarla de manera contundente cuando deja claro que:

las plantas existen para los animales y los animales para los hombres, los domésticos para su servicio y alimentación, y los silvestres, si no todos, al menos la mayor parte de ellos, para su alimentación y otras ayudas, para que les provean vestido y otros instrumentos. Si entonces la naturaleza jamás hace nada incompleto ni en vano, es forzoso que haya producido todas estas mismas cosas en vista del género humano.

Pues bien, admitir que Aristóteles sostiene su concepción de derecho natural argumentando una comunidad de hombres y animales como lo hace Empédocles parece un tanto temerario. ¿Cuál sería la conjetura que subyace en esta extraña alusión? Es posible exhibir dos razones señaladas por dos autores en artículos cuidadosamente escritos. Son las siguientes:

(i) El objetivo de las referencias a Antígona, Empédocles y Alcidamas no era presentar los preceptos que Aristóteles sostenía, sino demostrar la concepción de ley natural a partir de raigambres familiares. ${ }^{13}$

${ }^{12}$ D.K. = Diels-Krans (Die Fragmente der Vorsokratiker), en la bibliografía se incluye la referencia de la versión en francés de J.-P. Dumont, Les Présocratiques.

${ }^{13}$ F.D. Miller Jr., op. cit., p. 283. 
(ii) Los casos de Antígona y Empédocles no serían, a los ojos de Aristóteles, como sostienen diversos comentaristas, ejemplos de leyes naturales inmutables, sino solamente ejemplos de interpretación del derecho natural de los cuales él mismo echa mano: "es tan sólo una interpretación, variable conforme a culturas y épocas, de un presentimiento [la ley natural] que se impone a nuestro espíritu". ${ }^{14}$

En relación con (i), puede incluso entenderse como un argumento que merecería tenerse en consideración, aunque tan sólo desde el punto de vista retórico (lo que parece indicar una clara ruptura con los tratamientos posteriores de las obras éticas). Sin embargo, eso no garantiza de ninguna forma la autoridad y la coherencia de la Retórica con las teorías subsecuentes de la ley natural [en Aristóteles]. Miller asegura que la referencia a Antígona y Alcidamas sugiere que la ley natural tiene origen divino, ${ }^{15}$ pero que eso no está explícito en la Retórica. ¿Tendría que estarlo? Esa indagación se retomará más adelante.

En cuanto a (ii), cla ley natural sería realmente un presentimiento que se impone al espíritu de los hombres y que debería ser interpretada según épocas y culturas? Quizá, pero en este caso los ejemplos mencionados por Aristóteles como mínimo, no serían muy felices. La respuesta, en este caso, es más histórica que filosófica. Aunque Sófocles y Empédocles estuvieron separados geográficamente, los dos pertenecieron a una misma cultura, la griega, y a la misma época, el siglo $\mathrm{V}$ a.C. ¿Será posible deducir de la obra de Sófocles alguna prohibición de

${ }^{14}$ P. Destrée, "Aristote et la question du droit naturel", pp. 12-13. Destrée defiende la lectura de la Retórica (cfr. 1373b5-9) como parte del discurso aristotélico y afirma que "el derecho natural es como una exigencia que se impone al pensamiento o al sentimiento" (p. 13) cuando hacemos preguntas "sobre lo que es justo o injusto hacer. Pero eso no quiere decir que haya leyes inmutables: precisamente, como sugiere el verbo manteuesthai, se trata de interpretar esas exigencias, como el adivino debe interpretar los signos o los sueños" (p. 13). Aunque envolvente, esta solución no parece ser la más admisible, pues como observa Brunschwig, op. cit., p. 145, cuando Aristóteles aconseja al juez que tome en consideración la intención del legislador, "le aconseja implícitamente que no confie en 'intuiciones proféticas' que, como cualquier otro, él puede pensar que posee".

${ }^{15} \mathrm{El}$ texto no parece sugerir que la ley natural tenga origen divino. El texto afirma que la ley natural es la ley divina: "eso es lo que la Antígona de Sófocles quiere dar a entender cuando dice que el funeral de Polinices era una acción justa en relación con la prohibición: ella quiere decir que era justo por naturaleza" (Ret. 1373b911). Era naturalmente justo, o sea, era un derecho natural, una ley natural, no originaria del derecho divino, sino la propia ley divina, "ley no de hoy, ni de ayer, sino eterna..." (Antígona, cfr. la cita de la p. 143). 
matar animales (cuyo origen, según Empédocles, se encuentre en la ley eterna que se extiende en todos los sentidos a través del éter, y que rige desde lejos también a la tierra inmensa) que sea análoga a la distinción que él hace en Antígona, entre la ley que dictan los hombres y la ley no escrita, inmemorial, eterna, divina, la cual sirve de soporte para que Antígona tenga el derecho de no dejar insepulto el cadáver de su hermano Polinices? Difícilmente. Culturalmente el derecho de enterrar a los seres queridos era algo que, en el mundo griego, tenía el estatus de ley inmemorial, incontrovertible y no escrita, ${ }^{16}$ común a todos; la prohibición de matar animales por la existencia de una comunidad de hombres y animales, aunque estuvo presente en otra tradición filosófica y religiosa griega, no era común a todos, ni al mismo Aristóteles según el pasaje ya citado de la Política. Aristóteles debería hacer mención de ejemplos de culturas diferentes, de épocas distintas, lo cual, seguramente, no ocurre en el contexto construido por él, si tal fuera su pretensión. Todo eso conduce a presumir el carácter inadecuado de la Retórica como un momento en la elaboración de la doctrina del derecho natural en Aristóteles.

Poco antes se explicó que si la ley natural posee origen divino, eso no es evidente en la Retórica. Más bien, lo que debe sostener el carácter divino de la ley natural no es esta obra aristotélica — seguramente no es su pretensión-, sino la tragedia que utiliza para "justificar" la existencia de tal ley natural. Y eso trae más dificultades a aquellos que no rechazan la Retórica por considerar que esta obra posee una función importante en lo concerniente a esta temática. ¿Por qué?

${ }^{16}$ A título de esclarecimento, es importante constatar que hay una distinción clara entre la Retórica I 10 y I 13 en lo que concierne a la ley común y a la ley particular, que acompaña un cambio de estatus de la ley no escrita. En (a) I 10 hay, por un lado, la ley particular, propia de cada ciudad y, por otro, la ley común (consentida por todos). En (b) I 13, esta distinción sufre un cambio: (i) en primer lugar, surge la ley particular que, en este segundo momento, puede ser escrita o no escrita (las costumbres), y, (ii) en segundo lugar, la ley común, o sea, la ley natural, de la cual todos los hombres poseen un sentimiento natural y común, aun cuando no existe ninguna comunidad o contrato. En la segunda distinción (i y ii), el derecho de asegurar la sepultura a los muertos representa la ley natural, mientras que en la primera distinción este derecho es representado por la ley común. En la primera distinción (a), la ley común [natural] es la ley no escrita. En la segunda distinción (b), la ley no escrita se encuentra fuera del ámbito de la ley natural (común), pues esta ley no escrita difiere de la ley no escrita de la primera distinción (a) por el hecho de reflexionar sobre las costumbres inherentes a cada pueblo, mientras que la ley no escrita de la primera distinción refleja lo que es común a todos. El ejemplo de Antígona de Sófocles representa la ley consentida por todos (común) de (a) y la ley común (natural) de (b).

Diánoia, vol. LIV, no. 63 (noviembre 2009). 
Por un motivo de hecho sencillo: que la ley no escrita, eterna, válida para todos, a la que Antígona hace alusión es la ley divina (seguramente algo no ignorado por Aristóteles):

No fue Zeus en modo alguno el que decretó esto, ni la Justicia, que cohabita con las divinidades de allá abajo; de ningún modo fijaron estas leyes entre los hombres. Y no pensaba yo que tus proclamas [de Creonte] tuvieran una fuerza tal que siendo mortal se pudiera pasar por encima de las leyes no escritas y firmes de los dioses. No son de hoy ni de ayer sino de siempre estas cosas, y nadie sabe a partir de cuándo pudieron aparecer. No había yo, por temer el parecer de hombre alguno, de pagar ante los dioses el castigo por esto. (450-459)

Se podría argumentar que Aristóteles establece sólo una analogía entre la ley divina de Sófocles y la ley natural como él la entiende; pero esta ley divina en Sófocles no es la ley natural en el corpus aristotelicum como un todo (lo es solamente en la Retórica). Por consiguiente, la analogía estaría destinada al fracaso; no puede existir una solución de continuidad entre el fragmento de la Retórica y el pasaje del capítulo 10 del libro V de la Ethica Nicomachea. La ley natural es variable; sin embargo, la divina no. Eso queda expuesto de manera evidente por Aristóteles mismo en EN 1134b28-30, donde aparece con claridad la afirmación de que en el mundo sublunar existe un justo natural, justo natural expuesto a cambios, a la variación, lo que no es, en sus palabras, absolutamente el caso cuando se trata de un derecho divino, de una ley divina, por sí sola inmutable. ${ }^{17}$

Los tres fragmentos en la Ret. I 10, 13 y 15 no parecen dar apoyo, en modo alguno, a los que avistan en ellas, por parte de Aristóteles, la comprensión legítima, consistente y coherente de una doctrina acerca del derecho natural. En I 13, las referencias a Antígona, Empédocles y Alcidamas no pueden ser vistas como un abordaje realmente esencial para sostener tal doctrina por los motivos señalados antes, pues carecen de fundamentos que sirvan de apoyo para las reflexiones sobre el tema en las obras propiamente éticas. El pasaje contenido en I 15, donde afloran consejos de cómo hacer uso de las leyes (o positivas o comunes [naturales]) para obtener un mejor resultado en la práctica jurídica, en los tribunales, tiene un carácter eminentemente retórico y no propicia ningún entendimiento mayor en relación con un conocimiento categórico del asunto. En cuanto al primer pasaje, aunque colocado en el interior de un contexto que también busca establecer definiciones de cuño

${ }^{17}$ Para los dioses, lo natural es inmutable. En este mundo, el derecho que es natural está sujeto a cambios. 
retórico, es dudoso que permita un análisis un poco más próximo, se puede decir, a $E N$ y a $M M$, si intentamos comprender el "aparentan ser reconocidas" como algo que no es del todo absoluto, dejando espacio para casos alternativos. Sin embargo, eso no parece del todo verosímil.

Pero antes de continuar, es importante subrayar que el rechazo de la Retórica como uno de los momentos de la discusión de Aristóteles sobre el derecho natural no presupone, necesariamente, las tesis de aquellos que conciben el derecho natural como una norma inmanente específica de cada cultura. ${ }^{18}$ Para un análisis de este problema es imprescindible retornar al famoso pasaje aristotélico de $E N$ 1134b18-1135a5 junto con el de $M M$.

\section{El derecho natural en las éticas aristotélicas y en la Política}

En la medida en que la Retórica no puede servir a nuestras pretensiones, se debe encontrar en $E N$ 1134b18-1135a5 lo que realmente Aristóteles entiende por derecho natural y observar en qué medida tal concepción puede encontrar soporte en Magna Moralia, pues con estos textos se puede llegar a concluir cuán consistente puede ser la visión aristotélica.

El texto empieza por establecer, dentro de la justicia política, una división de la justicia que aparece bajo dos aspectos: natural, o sea, la justicia que en todo lugar (pantachoũ) tiene la misma fuerza (dúna$\mathrm{min}$ ), sin depender de cualquier opinión particular; y legal, cuyo origen puede ser indiferente, pero que, una vez establecida, se impone: 19 "por ejemplo, que el rescate se haga por una mina, o sacrificar una cabra y no dos ovejas. E, incluso, todas las leyes que establecen para los casos particulares, como, por ejemplo, sacrificar en honor de Brásidas; y las que tienen forma de decreto". (1134b21-24)

Como el pasaje indicado pone en evidencia, todas las leyes particulares, específicas de una determinada comunidad, o sea, el derecho positivo propiamente dicho, en sí mismo es variable temporal y geográficamente. Ese derecho positivo es, según Aristóteles, el único que existe, en la opinión de algunas determinadas personas; es el caso de los sofis-

${ }^{18}$ Como bien lo observó P. Destrée, op. cit., p. 8.

${ }^{19}$ Para una interpretación distinta en relación con los dos aspectos de lo justo político, natural y legal, véase R. Bodéüs, "The Natural Foundations of Right and Aristotelian Philosophy", de modo especial las pp. 71, 72, 79 y 80. Para Bodéüs, la tesis que opone la justicia natural a la justicia legal es cuestionable, porque lo que ocurre de hecho es una distinción "en el interior del derecho positivo entre lo que es natural y lo que es legal” (p. 71).

Diánoia, vol. LIV, no. 63 (noviembre 2009). 
tas, los cuales, como Protágoras, juzgan que el derecho debe ajustarse a las costumbres morales que se originan en la tradición y que el nómos es absolutamente fundamental a la vida de la sociedad, nómos éste que obedece a las particularidades de tal sociedad. En su comprensión, no es posible imaginar otro tipo de derecho, en su caso, el derecho natural, pues éste es inmutable y tiene "en todas partes la misma fuerza" (kaì pantachoũ tèn autẽn échei dúnamin (b25-26)), según se explicita en el ejemplo del fuego que quema del mismo modo "tanto aquí como en Persia". Sin embargo, para Aristóteles, la afirmación de que el derecho es eminentemente variable no es del todo razonable, al menos en relación con los dioses como hemos visto anteriormente. ${ }^{20}$ Entre nosotros, hay un derecho natural y tal derecho es variable (kinẽtón), ${ }^{21}$ ya que es perfectamente factible diferenciar lo que es natural de lo que no lo es: "Y entre las cosas que pueden ser de otra manera es evidente cuál es natural y cuál no lo es, sino que es legal y por convención, pese a que ambas son igualmente mudables" (b30-33).

John Burnet hace una interesante observación ${ }^{22}$ cuando subraya que Aristóteles quiere decir, en la oración que inicia con poîon (b30), específicamente al referirse a las cosas que pueden ser de otro modo,

${ }^{20}$ Según Bodéüs, Éthique à Nicomaque, p. 261, n. 2, "lo justo no se compara, como el fuego, a la naturaleza inmutable de lo divino; forma parte de las realidades humanas, siempre cambiantes, que son, sin embargo, por una parte, naturales". Eso presupone que la realidad humana, teniendo como referencia la realidad divina, es imperfecta. Tal vez, en ese sentido, la mutabilidad de lo justo por naturaleza se debería antes a la naturaleza imperfecta de lo humano y no a lo que es justo en sí mismo.

${ }^{21}$ En su comentario a la Ethica Nicomachea (Commentaria In Aristotelem Sententia libri Ethicorum), Tomás de Aquino examina y comenta cuál sería la intención de Aristóteles al afirmar que las cosas que son justas por naturaleza están también sujetas a mudanza y variación. Si, por un lado, las cosas que ocurren en nosotros la mayoría de las veces son naturales, lo que Aristóteles verdaderamente tiene en mente es que las esencias de las cosas sujetas a cambios son inmutables, pues la "verdadera naturaleza del hombre" no está sujeta, de modo alguno, a cualquier tipo de variación, ya que, por ejemplo, el hombre es naturalmente un animal, aunque sigue una naturaleza como disposiciones, acciones y movimiento que son variables en menores instancias. Igualmente, "las acciones pertenecientes a la verdadera naturaleza de la justicia no pueden ser mudadas de ningún modo [...], mientras las acciones que siguen (de la naturaleza de la justicia) son en algunos casos variables" (Sententia Ethic., lib. 5, 1. 12, n. 14). Entonces, la ley natural sería absolutamente inmutable en los dos aspectos en que se presenta: (a) es inmutable en sus primeros principios universales; (b) es inmutable cuando su validez es demostrada la mayoría de las veces.

${ }^{22}$ En la nota referente al § 4 de Aristóteles, The Ethics of Aristotle, p. 234. 
simplemente hõs epì tò polú. Lo que ocurre en la mayoría de las veces puede, eventualmente, no ocurrir u ocurrir de otro modo. Eso es importante, porque aunque la expresión hõs epì tò polú no aparezca "literalmente", como se ha observado antes, ella está implícita en el argumento y retoma lo que aparece literalmente en $M M$. Ahí, la expresión "la mayoría de las veces" aparece dos veces, y es importante recordar que la primera vez que esa expresión se presenta, remite al ejemplo de la capacidad de ser ambidextro, ${ }^{23}$ al afirmar que "la mayoría de las veces y la mayor parte del tiempo", la mano izquierda y la mano derecha conservan sus características propias y eso por naturaleza (por naturaleza, la mano derecha es superior [beltíó] a la izquierda). La mano derecha es naturalmente superior a la izquierda, aunque se pueda utilizar la mano izquierda del mismo modo que la derecha, ejecutando todo como la derecha lo haría, de la misma manera que "la justicia natural es mejor [superior] que la legal" ( $M M$ 1195a6).

No es sorprendente, entonces, que después del pasaje señalado (b30-33), que habla de lo natural que puede ser de otro modo, Aristóteles presente el mismo ejemplo (pues "en lo demás se aplicará la misma distinción") de la capacidad de ser ambidextro, sólo con una variación terminológica, pues al contrario de superior (beltíõ), él utiliza kreíttõn (más fuerte); es decir, si es verdad que la mano derecha es más fuerte que la izquierda, nada impide, sin embargo, que nos sea posible tornarnos ambidextros (b33-35). En $M M$, la analogía inmediata se hace con lo justo natural, presentado como lo "justo la mayoría de las veces". En $E N$ se da de otra forma, pues la referencia que sigue no es lo justo por naturaleza, sino el derecho positivo, lo justo legal, dependiente de la convención y del interés, donde se establece una analogía entre ello y las medidas que sirven para medir el vino o el trigo, medidas que no son iguales en todas partes, de la misma manera que el derecho positivo, pues "las normas de justicia no naturales, sino humanas, no son idénticas en todas partes. $\mathrm{Y}$ es que tampoco lo son las constituciones políticas." ${ }^{24}$ De pronto, mientras que en Magna Moralia se pasa de la capacidad de ser ambidextro a lo justo natural, en Ethica Nicomachea el

\footnotetext{
${ }^{23}$ Para un interesante análisis de la superioridad de la mano derecha sobre la izquierda en los escritos biológicos de Aristóteles, con una justificación teleológica de tal superioridad, indagando si de ahí es factible sacar conclusiones normativas, véase F.D. Miller Jr., op. cit., p. 289 ss. La interpretación general de Miller presupone una visión teleológica de la naturaleza humana y de la pólis, lo que permitiría un abordaje coherente y razonable de la ley natural y de la justicia aristotélica (p. 306).

${ }^{24}$ Todo el pasaje: $1134 \mathrm{~b} 35-1135 \mathrm{a} 5$.
} 
paso siguiente al ejemplo de la mano derecha y de la izquierda remite al otro tipo de lo justo diferente del natural, o sea, al justo legal, como si en la primera hubiera alguna urgencia por destacar el carácter fundamental de lo justo natural, caracterizado por la expresión hõs epì tò polú, y en la segunda hubiera alguna urgencia por anteponer lo justo legal frente a lo justo natural, anteposición marcadamente negativa, donde está señalado el aspecto metafóricamente deletéreo de lo justo legal con relación a lo justo natural ${ }^{25}$ que debe estar, necesariamente, ligado a la frase que cierra el pasaje: allà mía mónon pantachoũ epeì katà phúsin hẽ arístẽ: "sino que de ellas [de las constituciones] sólo una es la mejor en todas partes por naturaleza". Lo que se discute, en las dos obras éticas, aunque de modo distinto, es lo justo natural, y ese justo natural, que ocurre la mayoría de las veces, debe servir como momento inmediatamente anterior a la frase que afirma la existencia de una forma de gobierno, de una constitución que es, en todo y en cualquier lugar, la mejor.

Este justo natural, entonces, está íntimamente relacionado con la forma de gobierno que es, en todos los lugares, la mejor; sin embargo, parece fundamental precisar antes cuál es esta forma de gobierno,

${ }^{25}$ Lo que no es el caso de la perspectiva historicista de Joachim Ritter ("Le Droit naturel chez Aristote"), a la cual le parece extraño, y juzga sin sentido, establecer lo justo natural como algo que esté fuera de la comunidad política concreta, algo en sí y completamente aparte, pues está en todas las cosas que, en la ciudad, son consideradas justas: "[lo justo natural] solamente puede existir como el fundamento inmanente de la justicia en la ciudad". Por eso, Aristóteles puede afirmar que lo justo natural está también sometido a la mudanza, y por lo tanto es variable. No significa que lo justo es por naturaleza simplemente por el hecho de que en todos los lugares (pantachoũ) tiene la misma fuerza - lo cual pone en evidencia, es verdad, cierta universalidad-, ni que pueda enunciarse "separado de lo que se mueve y cambia", por un motivo de veras simple: "no se le puede separar de la realidad, de la cual forma parte el derecho establecido por prescripción, y oponerse a ella" (p. 438). No existe algún tipo de indeterminación en lo que dice respecto de lo justo natural, pues se da en el ámbito de la pólis, y este justo natural "está fundado en la naturaleza humana y tiene, en todos los lugares, la misma fuerza [. . . ]; lo justo por naturaleza no existe separado de lo que es variable, sino presente como tal en eso que es variable" (p. 446). Este historicismo, fundamentado en la concepción de una naturaleza inmanente, revela que "el concepto y el principio del derecho positivo es la naturaleza humana, y la naturaleza humana no es más que la vida ética de la ciudad" (p. 457). Un autor deudor de esta tradición comenzada por Ritter es Pierre Aubenque, especialmente en "La Loi selon Aristote", donde afirma "que nadie se opone a que se hable del derecho natural en Aristóteles, siempre que por ello se entienda no una trascendencia separada, sino una norma inmanente inspirada en su diversidad en la realidad de los derechos positivos" (p. 156).

Diánoia, vol. LIV, no. 63 (noviembre 2009). 
esta constitución, y de qué manera opera en su interior este justo por naturaleza que ocurre la mayoría de las veces.

La cuestión principal producto de la indagación sobre la mejor constitución procede del hecho de que Aristóteles -especialmente en la Política, el locus de análisis de las distintas formas de gobierno- en ningún momento pone en evidencia [con claridad] la superioridad de una constitución correcta sobre las demás. En Política III 1276b17-18 y 30 ss., cuando realiza la distinción entre el buen ciudadano (polítou spoudaíou) y el hombre de bien (andrós agathoú), afirma que la excelencia del buen ciudadano se modifica en función de la constitución a la cual pertenezca, de modo que no existe la posibilidad de atribuir al buen ciudadano una excelencia única. Pues bien, del mismo modo nos sería posible pensar que no existe una constitución excelente en relación con las demás. ${ }^{26}$ Sería posible pensarlo en la medida en que, más adelante, en el mismo libro III de la Política, encontramos la famosa distinción entre las constituciones, unas correctas (orthás) y otras que no lo son, que son desviaciones. Las constituciones correctas ${ }^{27}$ son tres en número (realeza [monarquía], aristocracia y politeía) y tienen como característica esencial mirar al bien común, y su rectitud está relacionada de manera evidente con el bien común. A final de cuentas, permiten la consecución de la eudaimonia y de la autosuficiencia: "Es evidente, entonces, que todas aquellas constituciones que miran al bien común son rectas, en cuanto se conforman a la justicia en sentido absoluto" (phaneròn toínun hõs hósai mèn politeîai tò koinẽi sumphéron skopoũsin, aũtai mèn orthaì tugchánousin oũsai katà tò haplõs díkaion). ${ }^{28}$

Al principio simplemente podríamos detenernos en tal distinción y reconocer que para Aristóteles no existirá una forma de constitución por excelencia, una constitución más perfecta que las demás, pues él reconoce en ese primer momento que hay tres constituciones rectas en la medida en que miran al bien común, pues el bien común es el principio que funda su rectitud. No obstante, en otro pasaje posterior, si bien de manera indirecta, señala que la realeza (basileia) es superior a

26 "Por eso la virtud del ciudadano está forzosamente en relación con el régimen. Por tanto, si hay varias formas de régimen, es evidente que no puede haber una virtud perfecta del buen ciudadano. En cambio afirmamos que el hombre de bien lo es conforme a una única virtud perfecta [...]. Así que es claro que se puede ser buen ciudadano sin poseer la virtud por la cual el hombre es bueno. No obstante, se puede abordar el mismo tema de otro modo, planteando el problema desde el punto de vista del régimen mejor" (1276b30-40).

${ }^{27}$ Pol. 1279a3 2ss.

${ }^{28}$ Pol. 1279a 17-19. 
las otras (Pol. IV 1288a15-19), pues comenta que puede ocurrir el caso de que un individuo o un linaje sea de tal modo superior en virtud, que sería justo que el poder le fuera concedido a ese individuo o a ese linaje. Ésa es claramente una preferencia otorgada a la realeza y a la aristocracia en detrimento de la politeía. No es un pasaje aislado, pues en 1289a25-37 reitera, con otras palabras, lo que acaba de mencionar:

Puesto que en nuestra primera indagación sobre las constituciones distinguimos tres constituciones rectas, a saber, realeza, aristocracia y politeía, así como tres desviaciones de ellas - tiranía de la realeza, oligarquía de la aristocracia y democracia de la politeía - y como ya hablamos sobre la aristocracia y la realeza (ya que examinar la constitución mejor es lo mismo que hablar sobre los regímenes así denominados; cada uno de ellos, en efecto, tiende a instituirse con una virtud provista de recursos), y puesto que antes ya precisamos en qué difieren entre sí la aristocracia y la realeza y cuándo hay que adoptar la realeza, queda por tratar la politeía, a la que se denomina con el nombre común a todas [...]

Parece que este tipo de argumentación desarrollado en los últimos pasajes citados indica el establecimiento de una jerarquía de las formas correctas de constitución, de primacía de la realeza y de la aristocracia con relación a la politeía desde el punto de vista de su excelencia. Sin embargo, muchas veces los caminos de Aristóteles son tortuosos, pues a mitad del camino hay otra afirmación que hace que se restituya a esta tercera forma de constitución cierta dignidad que tienen las otras dos:

Puesto que tres son, según decimos, las constituciones rectas, forzoso es que la mejor de ellas sea la administrada por los mejores; $y$ tal es aquella en la que se da el caso de que un solo individuo o un linaje entero o una multitud de ciudadanos sobresale por su virtud, y donde unos pueden obedecer y otros mandar en aras de la vida más deseable. $(1288 \mathrm{a} 32-37)^{29}$

${ }^{29}$ La dignidad retomada parece sacarse de 1293b34, donde la politeía pasa a ser concebida como un gobierno mixto, o sea, una mezcla de oligarquía y democracia. Es difícil aceptar que una de las constituciones correctas del libro III sea ahora relegada a una mezcla de dos constituciones desviadas, sobre todo cuando se tiene en vista III 11, cuando Aristóteles argumenta claramente que las leyes pertenecientes a las constituciones correctas son justas y las pertenecientes a las constituciones desviadas, injustas. De hecho, éste es un problema que sale del cuadro general de este estudio; por lo tanto, no nos detendremos en eso. La explicación de esta incoherencia podría ser que Aristóteles haya abandonado verdaderamente su es- 
Estas oscilaciones aristotélicas con relación a la politeía son incómodas. Llega a alegar que la politeía y las formas derivadas de aristocracia, aunque no sean verdaderamente desviaciones, en realidad se apartan de la constitución más correcta (tẽs orthotátẽs politeías), la aristocracia perfecta, de modo que las enumera junto con las desviaciones, las cuales, a su vez, se cuentan como desviaciones de la aristocracia y la politeía. Ahora bien, la orthotátẽ politeía quizá sea la aristocracia perfecta de IV 2, pero ahí esta aristocracia perfecta tiene la compañía de otra constitución, la realeza, pues "considerar la constitución excelente es la misma cosa que hablar de las constituciones designadas por estos nombres". Eso abre la posibilidad de afirmar que, en última instancia, debido a la exclusión a la que sometió a la politeía, las constituciones verdaderamente excelentes serían la realeza absoluta y la verdadera aristocracia. ${ }^{30}$

Aun reconociendo estas aparentes incongruencias, aunque sin fijarse en ellas en función del objetivo de esta investigación, eso no impide que sean tres las constituciones correctas o una más perfecta que las otras dos. Lo que conviene destacar es que eso no impide el esfuerzo de comprender el sentido de "la constitución que es, en todas partes, por naturaleza, la mejor". La constitución que en todas las partes (pantachoũ $)^{31}$ es por naturaleza la mejor es la que presupone que lo justo natural es, en lo que concierne a cada sociedad o comunidad, no lo que debe ser interpretado, sino aquello que debe indicar lo que es justo la mayoría de las veces (hõs epì tò polú), según la literalidad de $M M$ y el espíritu de $E N$.

quema de III 7 (cfr. R. Robinson en su traducción comentada de la Política, Aristotle Politics. III and IV, p. 90).

${ }^{30}$ Es la tesis de D. Keyt, "Aristotle's Theory of Distributive Justice", p. 257, n. 43: "Con todo, la incompatibilidad aducida desaparece una vez que se observa que 'la mejor constitución' es el género del cual las especies son la realeza absoluta y la aristocracia verdadera." Sobre la realeza absoluta, cfr. Política III 16. Para una mayor elucidación de esta cuestión, véase Aristóteles, The Politics of Aristotle, vol. 4, p. 144, n. 30.

${ }^{31}$ A partir del artículo ya citado de P. Aubenque, "La Loi selon Aristote", p. 154, hubo una discusión sobre el sentido de pantachoũ. En ese artículo, Aubenque dio a pantachoũ un sentido distributivo, y al colectivo, "de todas partes" le dio el de cada vez ("la mejor constitución es, cada vez, la que es conforme a la naturaleza del país y de sus habitantes"). Para una crítica incisiva, véase P. Destrée, op. cit., pp. 6, 7 y 14. Aubenque abandonó esta interpretación en "¿Aristóteles era comunitarista?", p. 19, n. 17. Aunque la haya abandonado, Bodéüs la retomó en la traducción de la Ethica Nicomachea: "pantachoũ no quiere decir (colectivamente) en todas partes indiferentemente, sino (de manera distributiva) en cada parte" (Aristóteles, Éthique à Nicomaque, p. 263, n. 2). 
Como bien ha observado Léo Strauss, ${ }^{32}$ no es suficiente afirmar que es necesario ser justo o que no debemos herir a nadie con una barra de hierro; eso enuncia una regla general, pero tal regla general depende de las circunstancias concretas en que la justicia es aplicada. Sin embargo, la aplicación de la justicia también depende de la orientación de lo justo natural. No obstante, esta aplicación no se da de la misma manera en todos los lugares - lo justo natural solamente mantiene por analogía ${ }^{33}$ la misma fuerza en todos los lugares-, sino en conformidad con el régimen político, esto es, con la constitución correcta, por naturaleza la mejor, en función de la cual determinado individuo puede ser tomado como un buen ciudadano y en las circunstancias en que cada constitución se desarrolla. Lo que caracteriza a las constituciones correctas es la consecución del bien común, y para corregirlo es necesario que la comunidad esté fundada en reglas de justicia. Estas reglas de justicia están referidas, ellas mismas, a lo justo natural que, por analogía, tiene en todos los lugares la misma fuerza. La existencia de distintas constituciones correctas, así como de las diferentes aplicaciones de la justicia en función de las circunstancias particulares de ahí derivadas, explica la variabilidad, la inestabilidad de lo que es justo por naturaleza.

Lo justo natural puede servir como orientación sólo por el hecho de que no se da necesariamente todas las veces, sino la mayoría de las veces. La proposición debería funcionar, entonces, de esta forma: ser justo la mayoría de las veces es realizar y en las circunstancias z en la constitución correcta $w$ (la mejor por ser correcta es mejor, por naturaleza, en todas partes, pues tiene en vista el bien común). Eso tiene variaciones. Lo que no cambia es el "imperativo": es necesario ser justo, o es necesario realizar el bien común, o que no debemos herir a nadie con una arma de hierro [la mayoría de las veces] (pero eso, a final de cuentas, no pasaría de ser un consejo general que no puede abarcar todas las circunstancias relacionadas). ${ }^{34}$ Luego, ello no es una norma inmanente (o un ideal regulador), incluso no existe una separación radical de lo justo (derecho) natural y de lo justo (derecho) legal. Lo justo natural orienta y ordena ${ }^{35}$ lo justo legal, y los dos son cambiantes

${ }^{32}$ Strauss, Droit naturel et histoire, p. 148.

${ }^{33}$ Sobre este tipo de analogía que encontramos en determinadas pasajes de la Generación de los animales (780b8-9, 784b15, 785b13, 733b14) y en la Generación y corrupción (318b23-24), o en la Política (1323b35), véase R. Bodéüs, "The Natural Foundations of Right and Aristotelian Philosophy", p. 82.

${ }^{34}$ Cfr. Ret. 1374a 31-b1.

${ }^{35}$ Lo justo natural orienta y ordena lo justo legal. Aunque lo justo legal "es lo que 
en función del carácter hõs epì tò polú ${ }^{36}$ de lo justo natural y del estatus mismo de lo justo legal.

De esta forma, tendríamos:

(a) Lo justo natural tiene, por analogía, en todos los lugares (pantachoũ) la misma fuerza y es variable (kinẽtón).

(b) Hay solamente una forma de gobierno (constitución) que es, en todas partes (pantachoũ), por naturaleza, la mejor.

Por (a) debe entenderse que lo justo natural tiene, por analogía, la misma fuerza en todos los lugares, y funciona la mayoría de las veces de este modo y no de otro y exactamente por este motivo es variable, pues no está sometido a ninguna forma de necesidad, de manera que comporta la variabilidad (kinẽtón) y tiene que estar relacionado con (b), ya que existen distintas formas correctas de constitución, distintas formas que presuponen formas diferentes de aplicación de lo justo, pero que dependen de la orientación, de la indicación de lo justo natural. Esta orientación de lo justo natural se adapta "de acuerdo con la forma de la piedra", como la regla de plomo de Lesbos, ${ }^{37}$ o sea, las aplicaciones

en su origen puede ser indiferentemente aquí o allí, pero una vez establecido, se impone", no excluye la posibilidad de que lo justo natural sea legal o que ordene en vista del bien común.

${ }^{36}$ Existen comentaristas (cfr. Destrée, op. cit, p. 4) que creen que la Magna Moralia minimiza la movilidad o variabilidad del derecho natural. Eso podría ocurrir por el hecho de que Destrée afirma que aunque existan cambios en función de nuestra utilización, aun así existe algo que es justo de manera permanente la mayoría de las veces. Ahora bien, eso, aunque suponga una minimización del carácter variable de lo justo natural, no quita del todo este carácter. Al contrario, aquello que se da la mayoría de las veces presupone el cambio, pues orienta de modo general lo que debe ser aplicado, tomando en consideración las circunstancias particulares. Destrée afirma que el "autor minimiza el sentido de kinêtòn en la medida en que la mudanza no está relacionada con la naturaleza, sino con nuestra utilización [...]; el hombre que es naturalmente diestro está siempre en posibilidad de volverse ambidextro. En este contexto, la capacidad de ser ambidextro es comprendida solamente como una excepción la regla normal de que lo más frecuente es el hecho de ser diestro" (pp. 4-5). Sin embargo, este tipo de interpretación puede ignorar el hecho de que los ejemplos de ambidextros en los estudios biológicos difícilmente pueden ser retomados, por analogía, en el ámbito de la filosofía práctica, espacio de la contingencia.

${ }^{37}$ EN 1137b29-32, este tipo de consideración se confirma a través de la presentación inmediatamente anterior de la epieíkeia (equidad), donde se constata que la ley es general (kathólou), y esta generalidad es la causa de su deficiencia, pues no puede aplicarse a todos los casos particulares y, por consiguiente, debe ser corregida 
de lo justo se adaptan a las circunstancias de las constituciones, o regímenes políticos, correctas. Si es correcta, ella es la mejor en todas las partes, por naturaleza.

Desde este punto de vista, la concepción aristotélica sobre el derecho natural parece encontrar una justificación plausible, consistente y coherente en el interior de la Ethica Nicomachea y en perfecta consonancia con el que es explicado en la Magna Moralia, así como con toda la argumentación referente a las formas de gobierno, o de constitución, desarrollada en la Política. Luego -y sólo para asegurar la veracidad del análisis realizado a lo largo del texto-, parece bastante prudente descartar la Retórica, pues la intención de esta obra, específicamente en los pasajes concernientes al tema, por los motivos ya mencionados no permite afirmar que ella contribuiría realmente a la consecución de una tesis aristotélica respecto del derecho natural.

Eso significa afirmar que la Retórica no presenta una solución de continuidad con la Ethica Nicomachea ni con la Magna Moralia acerca del estatus de lo justo por naturaleza. Estas últimas obras sostienen que lo justo natural es mutable - aunque sin excluir del todo la inmutabilidad, como en el caso de la capacidad de ser ambidextro- e incluyen la expresión "la mayoría de las veces" (hõs epì tò polú ), mientras que en la Retórica no sucede esto, pues en su contexto resalta la existencia de una ley común, universal, válida para todos indistintamente y, especialmente en el ámbito de la tragedia, esta ley común, ${ }^{38}$ universal, sostenida por Antígona en I 13, no es otra que la ley divina, lo que está claramente ausente de la Magna Moralia. En la EN, en lo referente a los dioses, lo natural es inmutable (como es también el caso en la Retórica), mientras que en este mundo, el mundo de las realidades propiamente humanas, lo justo natural está sujeto al cambio. Por lo tanto, en la Retórica, la ley natural está circunscrita a la ley divina; en la Ethica Nicomachea hay una clara distinción entre la esfera de lo divino (inmutable) y la esfera humana, donde lo justo natural es inmutable.

Además de esta diferencia fundamental de abordaje, tenemos los objetivos claros de los pasajes referentes a la Retórica I 10 y 15:

por el hombre sensato. Eso ocurre por la naturaleza del objeto, pues al no poder haber un enunciado general que se aplique indistintamente, debe limitarse a los casos que ocurren frecuentemente, o habitualmente [la mayoría de las veces]. Lo mismo ocurre con el phrónimos (el prudente), que tiene por objeto no solamente lo universal, sino también lo particular, ya que la acción se refiere a las cosas particulares. No basta decir que las carnes suaves son buenas para la salud, es necesario saber cuáles carnes son suaves (EN 1141b15-20).

${ }^{38}$ Véase la n. 15 de este artículo.

Diánoia, vol. LIV, no. 63 (noviembre 2009). 
(i) en I 10 Aristóteles trata cuestiones referentes a la acusación y a la defensa, y su disquisición tiene como telón de fondo un interés fundamentalmente retórico, enumerando y describiendo las premisas de los silogismos; y

(ii) en I 15, precisamente por el hecho de que la defensa del derecho natural, de una ley común, universal, válida incondicionalmente para todos, el recurso a la ley universal aparenta no ser más que un artificio retórico utilizable en el ámbito judicial, donde se emplean técnicas de persuasión/disuasión, pues, como menciona el texto, es preciso que se utilicen todos los procedimientos posibles para tener éxito en los tribunales. Si la ley escrita no es suficiente para ello, debo hacer alusión a una ley universal que me sea favorable.

\section{BIBLIOGRAFÍA}

Aristóteles, Ethica Nicomachea, ed. I. Bywater, Oxford University Press, Oxford, 1942 (Oxford Classical Texts).

, The Ethics of Aristotle, ed., introd. y notas J. Burnet, Ayer Company, Salem, Nuevo Hampshire, 1988.

—_ Ética a Nicómaco, introd., trad. y notas J.L. Calvo Martínez, Alianza, Madrid, 2001 (Clásicos de Grecia y Roma).

— Politics, ed. D. Ross, Oxford University Press, Oxford, 1957 (Oxford Classical Texts).

— - Política, introd., trad. y notas M.I. Santa Cruz y M.I. Crespo, Losada, Buenos Aires, 2005.

- The Politics of Aristotle, introd., pref. y notas W.L. Newman, Ayer Company, Salem, Nuevo Hampshire, 1985, 4 vols.

- Politics III and IV, trad., introd. y comentarios R. Robinson, ensayo complementario de D. Keyt, Clarendon, Oxford, 1995 (Clarendon Aristotle Series).

—_, Magna Moralia, trad. G. Cyril Armstrong, Loeb Classical Library, Harvard, Cambridge, Mass., 1990 (Loeb Classical Library, Aristotle XVIII).

—, Ars Rhetorica, ed. W.D. Ross, Oxford University Press, Oxford, 1959 (Oxford Classical Texts).

— Retórica, introd., trad. y notas Q. Racionero, Gredos, Madrid, 1990 (Biblioteca Clásica Gredos, 142).

Aubenque, P., "La Loi selon Aristote", Archives de Philosophie du Droit, no. 25, 1980, pp. 147-157.

— , "Aristóteles era comunitarista?", Dissertatio, nos. 19-20, 2004, pp. 5-20. Bodéüs, R., "The Natural Foundations of Right and Aristotelian Philosophy", en R. Bartlett y S.D. Collins (comps.), Action and Contemplation. Studies in the 
Moral and Political Thought of Aristotle, State University of New York Press, Nueva York, 1999, pp. 69-103.

Brunschwig, J., "Rule and Exception: On the Aristotelian Theory of Equity", en M. Frede y G. Striker (comps.), Rationality in Greek Tought, Clarendon, Oxford, 1996, pp. 115-155.

Cooper, J.M., “The Magna Moralia and Aristotle's Moral Philosophy”, en T.H. Irwin (comp.), Classical Philosophy, 5: Aristotle's Ethics, Garland, Nueva York, 1995, pp. 1-23.

Destrée, P., "Aristote et la question du droit naturel (EN V, 10, 1134b181135a5)", en Cahiers du Centre d'études sur la pensée antique "kairos kai logos", no. 9, 1997, pp. 1-20.

Dumont, J.-P. (comp.), Les Présocratiques, Gallimard, París, 1988 (Bibliothèque de la Pléiade).

Keyt, D., "Aristotle's Theory of Distributive Justice", en Keyt y Miller, A Companion to Aristotle Politics, pp. 238-278.

Keyt, D. y F.D. Miller Jr. (comps.), A Companion to Aristotle Politics, Blackwell, Oxford/Cambridge, 1991.

Miller, F.D. Jr., "Aristotle on Natural Law and Justice", en Keyt y Miller, A Companion to Aristotle Politics, pp. 279-306.

Ritter, J., "Le Droit naturel chez Aristote", Archives de philosophie, no. 32, cahier III, 1969, pp. 416-457.

Romilly, J. de, La Loi dans la pensée grecque, Les Belles Lettres, París, 2001.

Sófocles, Áyax, Las Traquinias, Antígona, Edipo Rey, trad. y pról. José María Lucas de Dios, Alianza, Madrid, 1998 (Clásicos de Grecia y Roma).

Strauss, L., Droit naturel et histoire, Flammarion, París, 1986.

Tomás de Aquino, Sententia libri Ethicorum, en Opera omnia (Edición Leonina), tomo 47, Commissio Leonina, ad Sanctae Sabinae, Roma, 1969.

- Commentary on Aristotle's Nicomachean Ethics, trad. C.I. Litzinger, Dumb Ox Books, Notre Dame, 1993.

Recibido el 28 de febrero de 2008; aceptado el 20 de enero de 2009. 